ISSN: 1641-4713; e-ISSN: 2081-1160

DOI: https://doi.org/10.36551/2081-1160.2021.27.31-48

\title{
Arte e artistas migrantes: Um universo simbólico na formação da sociedade brasileira
}

Art and Migrant Artists: A symbolic universe in the formation of Brazilian society

\author{
Mirian Silva Rossi \\ Universidade de São Paul, Brasil \\ ORCID iD: 0000-0001-7314-4687 \\ E-mail: misrossi@alumni.usp
}

Recepción: 21.12.2020

Aprobación: 30.06.2021

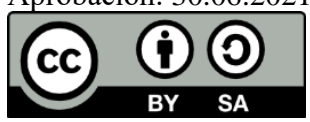

Resumo: : Muito se procurou e se procura as autênticas raízes da nossa nacionalidade. Esse tema se apresentou de forma mais abrangente nas primeiras décadas do século XX, levando a nossa intelectualidade a refletir sobre o que somos e o que não somos; entre reconhecer uma originalidade nacional ou aceitar as teorias estrangeiras. Na tentativa de compreender a cultura brasileira, produziram-se imagens e reflexões profundamente contrastantes entre si. Esta pesquisa tem por objetivo retomar esse debate, tendo como linha de argumentação o lugar que a arte e os artistas imigrantes em São Paulo ocuparam, no longo e contraditório processo de formação da sociedade brasileira. Transitando pelo universo simbólico do qual emergem as formas e as representações artísticas, as relações e as significações, este estudo parte do pressuposto de que a arte promove o encontro do homem consigo mesmo e com a sua cultura, e que as manifestações estéticas de uma sociedade, quando em sintonia com o momento histórico, são capazes de revelar a sua essência, no que ela tem de material e imaterial.

Palavras-chave: arte, cultura, identidade, imigração, sociedade brasileira..

Abstract: Much has been sought and searched for the true roots of our nationality. This theme
presented itself more comprehensively in the first decades of the twentieth century, leading our
intellectuals to reflect on what we are and what we are not; between recognizing a national
originality or accepting foreign theories. In an attempt to understand Brazilian culture, deeply
contrasting images and reflections were produced among themselves. This research resumes this
discussion, having as line of argument the place that art and immigrant artists in São Paulo occupied, 
in the long and contradictory process of formation of Brazilian society. Transiting through the symbolic universe from which emerge forms and artistic representations, relations and meanings, this study starts from the assumption that art promotes man's encounter with himself and with his culture, and that the aesthetic manifestations of a society, when in tune with the historical moment, are able to reveal its essence, in what it has of material and immaterial.

Keywords: art, culture, identity, immigration, Brazilian society.

Hipoteticamente, o tempo pode ser liso, duro ou macio. Mas neste mundo, a textura do tempo parece pegajosa. Porções da cidade aderem a algum momento da história e não se soltam.

Sonhos de Einstein (Lightman, 1996)

O final do século XIX e o começo do século XX foram marcados no Ocidente pela expansão das forças produtivas e pelo progresso material. As conquistas da industrialização, a evolução dos meios de transporte e comunicação, a expansão dos mercados, as inovações tecnológicas, científicas e culturais e o aumento populacional, acionavam a máquina da modernidade. O mundo vivia um tempo de euforia e a joie de vivre caracterizava a vida cotidiana, antes da crise que culminou com a Primeira Guerra Mundial.

A celebração do progresso aportou no Brasil como a materialização de uma civilização que tinha nos paradigmas culturais europeus, o seu modelo. (Needell, 1993), definindo de maneira clara o perfil mais marcante da nossa sociedade. Momento de questionamentos e inquietações, esse período expôs as dualidades, as contradições, os antagonismos e as tensões que permeavam as relações entre dominantes e dominados, opressores e oprimidos, estado e classes subalternas, nacionais e estrangeiros, que chegavam em grandes levas ao país.

Essa desarticulação, que caracterizou a sociedade brasileira da Belle Époque, desencadeou sucessivas convulsões em todos os níveis da vida pessoal, social e institucional, reforçando a insegurança de se estar vivendo simultaneamente em dois mundos, em um turbilhão de desintegração e mudanças, de dúvidas e de angústias. Essas ambiguidades dificultaram a necessária percepção da fusão de forças materiais e espirituais, da interdependência entre o indivíduo e o meio, da experiência de tempo e espaço, da consciência de si e dos outros, revelando uma sociedade que passava por profundas transformações, dividida entre o peso de uma herança européia e o desejo de reinterpretar o passado, de compreender a realidade brasileira, de exprimir a consciência social e de descobrir a autenticidade nacional.

Quem leia nossos livros, quem olhe nossas estátuas, quem contemple nossa arquitetura, encontra por tudo a alma europeia, [...] Tudo de empréstimo, tudo copiado, tudo decalcado... ... Por quê? O crítico superficial berrará que somos um povo de plagiários [...]. 
Nossa civilização transplantou-se para aqui, nas levas imigratórias, a velha cultura europeia, com todos os seus vícios e virtudes. (Del Picchia, 1920)

A percepção dessa complexa dualidade começou a ser questionada pela nossa intelectualidade, que passou a refletir sobre o que somos e o que não somos; entre reconhecer certa originalidade nacional ou aceitar as teorias estrangeiras, que viam na mistura um mal, e na diferença entre as raças um elemento fundamental. Na tentativa de se forjar a "alma nacional", compreender a cultura e o "caráter brasileiro", produziram-se imagens e reflexões sobre a nossa identidade, profundamente conflitantes entre si.

Paulo Prado, em seu Retrato do Brasil: ensaio sobre a tristeza brasileira, via na mescla de etnias presentes na nossa sociedade, "excessos de vida sensual", resultado do encontro do "português da governança e da fradaria", com o "clima, a terra, a mulher indígena ou a escrava africana", que, ao longo dos séculos, criou "uma raça triste", onde impera o "vício da imitação" (Prado, 2006).

Mário de Andrade, no primeiro prefácio de Macunaíma, nos diz que o "brasileiro não tem caráter". Caráter não apenas no sentido moral, mas no que ele chama de "entidade psíquica permanente", que se manifesta nos costumes, na ação exterior, no sentimento, na língua, na história, possui nem civilização própria nem consciência tradicional (M. de Andrade, 2016).

Em 1933, Gilberto Freyre publica Casa Grande e Senzala, tido como marco inaugural nas análises da cultura brasileira, que modificaria o enfoque da questão das raças formadoras do país: português, africano e indígena. A percepção positiva da mestiçagem e a reciprocidade das práticas culturais tributárias desse entrecruzamento eram vistas por Freyre como um traço "estruturante" e um elemento chave das relações étnicas no Brasil, expressando a ideia de uma "democracia racial". Para Freyre, era nas casas-grandes que melhor se exprimia o "caráter brasileiro: a nossa continuidade social” Freyre, G. 2006).

Sérgio Buarque de Holanda, em Raízes do Brasil (Holanda, S. B.1991), ressalta a necessidade de o país superar as raízes culturais ibéricas como condição para entrar na modernidade. Sua reflexão sobre a forma particular como o processo de implantação da cultura europeia foi historicamente consolidando-se no Brasil, destaca uma individualidade que traz, como traço constitutivo do brasileiro, características que o autor sintetiza na noção do "homem cordial", expressão tomada de Ribeiro Couto.

Quem somos nós afinal? Tristes, cordiais? Não temos caráter? Somos plagiadores? Somos uma democracia racial ou será que somos uns desterrados em nossa própria terra? É possível que sejamos um pouco de tudo o que se disse 
e se diz sobre nós, porque os elementos constitutivos da identidade brasileira não residem em uma igualdade ou harmonia, mas circulam por um terreno movediço em constante transformação. Nas suas múltiplas e complexas dimensões, entretanto, aflora um campo em que a conciliação mútua se expressou em formas e cores na união das diferenças. Nesse campo, a arte e o artista se mesclaram com o nacional e com o estrangeiro, e as manifestações estéticas foram marcadas pela confluência da percepção, representação e expressão próprias de cada um.

\section{UMA “NACIONALIDADE” SEM NAÇÃO}

Muito antes de nos tornarmos uma nação, as diferenças e os opostos iriam se fundir pela primeira vez, de maneira muito particular, nas Minas Gerais na metade do século XVIII. À grande imigração portuguesa (Gorender, 1985; Lima, 1985) juntaram-se os negros e os "homens das mais diversas procedências e raças: paulistas afeitos à vida rude, experimentados no sertão e na caça ao índio, brasileiros do Norte, boiadeiros, vadios do litoral, ciganos, judeus e cristãos-novos" (de Vasconcelos, 1969). A multiplicidade de culturas fez nascer nas Minas Gerais uma sociedade sui generis em efervescência e em constante mutação. Na sociedade mineradora, muito mais do que na sociedade canavieira, o branco português, persistentemente europeu e cristão nas suas formas decisivas de civilização, conviveu com o diverso à luz de novas experiências e novas situações, modificando, irreversivelmente, a face da colônia. Em Minas, a dor da escravidão pareceu atenuar-se na intensa miscigenação; uma espécie de remissão pelo desprezo à condição humana e pela violência do tráfico negreiro.

A composição desse mosaico, de elementos heterogêneos, não se fez pela harmonia, mas pela contradição, pela diferença, pelo contraste e pela resistência. Do entrelaçamento racial nasceu um novo homem: o mestiço. É nele que se equilibra a multiplicidade de etnias, que se somam os antagonismos, que harmonizam os opostos.

Das mãos desse mestiço renasce a arte do conflito, que assume características novas e inconfundíveis no barroco mineiro, constituindo-se meio de expressão ambivalente através do qual podemos pensar todo o processo social em trânsito. Sociedade, artista e arte se imbricam e se fundem na ambiguidade e nas incertezas, em um verdadeiro labirinto de significantes e significados. "Tudo nas Minas é antinômico, antagônico, contraditório, binário. Tudo, porém, conflui para sínteses perfeitas" (de Vasconcelos, 1969).

Se levarmos em conta que o barroco se associa à ruptura com as formas de equilíbrio e estabilidade, ao conflito e à contradição, às antíteses e aos 
paradoxos, estaremos falando da própria sociedade mineira. Assim como na sociedade, na arte há também a existência de elementos estranhos que se imbricam com relativa fartura no corpo do barroco. Tanto a sociedade quanto a arte nas Minas Gerais do século XVIII, nascem de semente importada, para florescer em nova atmosfera.

Ao contrário do barroco europeu, o barroco mineiro não se insere no contexto do absolutismo, da contrarreforma, nem é, tão pouco, instrumento das elites. Nas Minas, a arte do conflito se fez fronteira entre o popular e o erudito, entre o branco e o negro, entre o regional e o universal. $\mathrm{O}$ artista mulato, que pela sua própria essência e origem, poderia ter sido o elemento desestabilizador e contestador na sociedade colonial, passa a ser mais um elemento do sistema e não a sua contradição. Cobiçado pelas irmandades, esse mestiço alcançou a superação do étnico pelo cultural. Sob a égide dessas irmandades, movidas principalmente pela inspiração religiosa, uma brilhante geração de artesãos, arquitetos e pintores locais criaram um patrimônio cultural de enorme complexidade formal e riqueza plástica.

$\mathrm{O}$ artista mineiro nasce, cresce e vive numa sociedade barroca, onde as formas tendem a se liberar das rígidas imposições lineares e se desenvolvem de maneira difusa, ambígua e indefinível. Até mesmo a topografia das Minas Gerais parece encontrar correspondente na estética barroca. Os contornos suaves e sem arestas das montanhas das Gerais se debruçam sobre os vales, que se desenrolam entre avanços e recuos, até alcançar o horizonte. Como no barroco, a visão não se detém, e percorre a paisagem num indo e vindo sem fim, impregnando a alma do artista mineiro de suaves ondulações, sem atritos, numa sinuosidade difusa, que se faz presente, em especial, na arte religiosa barroca.

Os maiores artistas do barroco mineiro, Antônio Francisco Lisboa, o Aleijadinho (c.1738-1814), filho de pai português e de mãe escrava, africana de Mina, e Manuel da Costa Ataíde (1762-1837), tido como o principal pintor do barroco mineiro, nasceram escravos e eram mulatos. A sociedade certamente nunca os considerou inteiramente livres. Indefiníveis social e racialmente, nem pretos, nem brancos, nem escravos nem livres, como artistas admirados, como homens, repudiados.

Aos poucos os grilhões foram se quebrando, uma nova mentalidade foi surgindo, trazendo consigo uma verdadeira expressão de liberdade de criação, invenção e ousadia, que eclode em pleno regime de opressão: liberdade de infringir as regras trazidas pelo europeu, de criar soluções inesperadas, que se fazem presentes nas obras de Aleijadinho - nas talhas, nos adornos, nos relevos, nas curvas que se desdobram como se quisessem saltar os limites preestabelecidos, 
nas torres arredondadas das igrejas de São Francisco de Assis, de Ouro Preto e de São João d'El Rei, nas paredes que se curvam harmoniosamente na igreja do Rosário, de Ouro Preto ou nas cenas dos retábulos das igrejas de Nossa Senhora do Carmo de Sabará e de São Francisco, que já obedecem aos cânones do Rococó que, nas Minas Gerais se mesclou com o barroco.

A liberdade de expressão está presente, sobretudo, no Santuário de Bom Jesus d Matosinhos, localizado em Congonhas do Campo, que exibe no adro as esculturas de doze profetas do Antigo Testamento, executadas em pedra-sabão. O conjunto arquitetônico e paisagístico, considerado um dos pontos altos da produção de Aleijadinho, quando o seu estilo atinge a maturidade e o ápice de sua expressividade, incorpora, além do adro, a igreja e os grupos escultóricos em madeira policromada representando os passos da Paixão de Cristo, cenograficamente distribuídos em seis capelas. A primeira delas abriga a Última Ceia, que estabelece um ritmo visual criado pelas formas plásticas, conduzindo a nossa visão pelas mãos dos apóstolos, as quais se interligam em curvas suaves até Cristo, que se liga intimamente ao conjunto - pela direita, por São João, que reclina sua cabeça sobre seu ombro e, pela esquerda, por sua própria mão que se liga à mão de São Pedro. Os apóstolos assumem posições dinâmicas, caracterizadas pela gestualidade, e as suas cabeças fazem o mesmo jogo das mãos, formando um semicírculo ondulante em direção à cabeça de Cristo.

Essa capacidade inventiva, de traços híbridos e inusitados, nascida da conjunção de diferentes etnias e matrizes plásticas, desenvolvida em atmosfera brasileira, daria lugar, em poucos anos, a uma concepção estética regida por normas e convenções, simetria e proporcionalidade, importada da Europa.

\section{ENTRE VANGUARDA E TRADIÇÃO}

Em 1816, chegou ao Rio de Janeiro, capital do Império, a Missão Artística Francesa, que introduziu o ensino clássico e metodológico, mudando o panorama das artes no país e distanciando-se, radicalmente, da tradição barroca. A partir daí, a formação artística se caracterizou pela ênfase no racionalismo, no equilíbrio, na ordem, e na moderação, e o ensino oficial da corte iria moldar por longo tempo o aprendizado dos artistas brasileiros.

Ainda na última década do século XIX, a primeira do regime republicano, boa parte da produção pictórica tinha como pano de fundo um realismo que obedecia aos cânones técnicos acadêmicos e às convenções temáticas. Não se pensava ainda na dissociação entre o ver e o saber, entre a imagem e o conceito, entre 
a arte e a ciência. A exigência de um desenho bem cuidado, de uma perspectiva justa, da máxima correção na composição e no uso das cores, eram limites que se impunham ao artista, impedindo-o muitas vezes de revelar seus recursos próprios. $\mathrm{Na}$ indumentária e adereços dos retratados, nos pequenos registros da experiência cotidiana, na paisagem que já se perdeu, os detalhes recriam e identificam um momento passado, evidenciando o pertencimento dessa pintura a um tempo e a um lugar determinados.

Embora disseminada por todo o país, a corrente estética que caracterizou a Corte Imperial não aportou em São Paulo em toda a sua plenitude. Localizada em um ponto estratégico, que ocupa a confluência natural dos caminhos que comunicam o interior ao litoral, e favorecida pela conjuntura que se delineava, a cidade teve o seu progresso assegurado e a sua inserção em um universo cultural mais rico e diversificado que a envolveram em uma metamorfose própria. Essa situação privilegiada seria potencializada pela presença da ferrovia, tornando a cidade um entreposto obrigatório para o trânsito de mercadorias como a canade-açúcar e, especialmente, o café, um dos grandes, senão o maior responsável pela irrupção desenvolvimentista que tomou conta da cidade. A mão de obra imigrante, que chegava em grandes levas ao porto de Santos, fecha o vértice de um triângulo a partir do qual a cidade entrará em um processo de desenvolvimento irreversível.

O surto progressista projeta-se em todos os níveis da sociedade numa reação em cadeia. A presença na cidade do estrangeiro imigrante, alguns trazendo alguma experiência profissional, outros, ideais políticos que se disseminariam nas duas primeiras décadas do século XX, dá um novo tom à vida social da capital, introduzindo novos hábitos, novas posturas, novos tipos de festividades, novos relacionamentos familiares. Os meios de transporte e de comunicação aceleramse, cresce o número de estabelecimentos comerciais, de confeitarias e casas de chá, praças e jardins, teatros e clubes, que se somam aos primeiros cinematógrafos, às primeiras exposições artísticas e aos primeiros salões privados.

A partir daí, uma nova forma de sociabilidade seria engendrada, e a burguesia da república nascente aumenta em número e influência, buscando novas formas de participação, iniciando um processo de mudanças que se refletiriam sobremaneira no cotidiano dos paulistanos. Esse avanço permitiu que a cidade usufruísse dos benefícios da atividade agrária e industrial, abrindo espaço para que o campo artístico paulistano (Bourdieu, 1992, 1996; Bourdieu \& de Saint Martin, 1976) se desenvolvesse longe de uma instituição central de ensino, subordinada às estruturas de um poder político-econômico, fazendo com que a pro- 
dução pictórica se afastasse, de certa maneira, de uma concepção estética rigidamente dogmática.

Este fator desencadeou diversas e importantes consequências para o campo artístico paulistano, mediante a atuação das instituições de ensino e aperfeiçoamento artístico locais, como o Liceu de Artes e Ofícios, a Escola Profissional Masculina do Brás, o Pensionato Artístico - órgão oficial que subvencionava os estudos no exterior e os Cursos Livres, ministrados por artistas de renome, nacionais e estrangeiros, que desempenharam importante papel na formação dos jovens que se iniciavam nas artes plásticas.

Essas iniciativas, potencializadas pelas transformações pelas quais passava a capital paulista, favoreceram a constituição e o crescimento de novos setores sociais. Privilegiados pela concentração de renda e de consumo, esses grupos, compostos por uma elite que inclui os profissionais liberais, os intelectuais, membros do corpo do Estado e, sobretudo, homens de negócios como banqueiros, industriais e comerciantes, tiveram acentuada participação no desenvolvimento das atividades artísticas na capital de São Paulo.

Durante as três primeiras décadas do regime republicano São Paulo concentrou um considerável número de artistas nacionais e estrangeiros, compreendendo $55,4 \%$ e 44,6\% respectivamente, conforme amostragem da Tabela 1:

Tabela 1. Artistas ativos em São Paulo entre 1890 e 1920

\begin{tabular}{|l|c|c|}
\hline \multicolumn{1}{|c|}{ Procedência } & $\mathrm{n}^{\mathrm{o}}$ & $\%$ \\
\hline Brasil & 133 & 55,4 \\
\hline Itália & 61 & 25,0 \\
\hline Espanha & 12 & 5,0 \\
\hline Portugal & 11 & 4,6 \\
\hline França & 8 & 3,4 \\
\hline Outros países & 16 & 6,6 \\
\hline Totais & 241 & 100,0 \\
\hline
\end{tabular}

Fonte: Rossi, 2013.

Esses artistas, nacionais e estrangeiros, atuaram lado a lado no campo das representações estéticas, como atividade permanente e profissional, realizando exposições individuais e coletivas, expondo as suas obras nas vitrines da cidade, lecionando, executando encomendas e participando de concursos, de modo a trazer contribuições significativas para as artes plásticas brasileiras. 
Embora nascidos no Brasil, muitos artistas que fazem parte da amostragem denotam, pelos seus sobrenomes, a origem estrangeira, como Anita Malfatti, Augusto Hantz, Carlos Chambelland, Helios Seelinger, Hugo Adami, Nicota Bayeux, Pedro Weingärtner, Túlio Mugnaini, entre outros (Rossi, 2001).

Entre os artistas estrangeiros, muitos se fixaram definitivamente na capital, como a francesa Bertha Worms, o alemão George Fischer Elpons, o lituano Lasar Segall, que expôs pela primeira vez na capital, em março de 1913, e particularmente os italianos, com sedimentada cultura artística, como Alfredo Norfini, Angelo Cantu, Antonio Ferrigno, Antonio Rocco, Beniamino Parlagreco, Carlo De Servi, Enrico Vio, Giulio Starace, Menotti e Umberto Della Latta, Nicolo Petrilli, Rosalbino Santoro, entre muitos outros, legando uma grande contribuição para a arte nacional, o que por si é um testemunho da intensidade e do caráter multiforme da participação e integração italiana no país. Sua contribuição não se mede apenas pela quantidade e qualidade das obras deixadas em nossos acervos, mas também pela ação pedagógica dispensada aos jovens artistas nacionais, contribuindo para a afirmação de seu estilo e para o aperfeiçoamento de seus conhecimentos técnicos (Rossi, 2001).

Além dos artistas imigrantes que aqui residiam, o Brasil recebia artistas estrangeiros, em sua grande maioria europeus, que iam e vinham com certa regularidade. Muitos traziam a família, permanecendo no Brasil por meses ou até anos. Entre esses artistas itinerantes destacam-se Antonio Fernandez Gomez, Augustin e Pablo Salinas, Ernesto Valls, Richard Hall, Gabriel Biessy, Giuseppe Amisani, Luiz Graner, Nicola De Corsi, Nicola Fabricatore, Ribas Prats, Tomaso e Michele Cascella. (Rossi, 2001).

A ausência de uma instituição de ensino nos moldes da Academia Imperial de Belas Artes do Rio de Janeiro permitiu aos artistas que atuavam em São Paulo, distanciar-se de uma concepção estética imobilizada, alheia a novas correntes de expressão ou hostil a qualquer inovação.

Nas primeiras décadas do século XX, o artista vai conquistando maior liberdade para poder expressar o seu talento, o seu senso estético, o seu gesto individual e a sua emoção. Ao lado das cenas mitológicas, dos retratos oficiais e da representação de fatos históricos convenientes à exaltação cívica da República nascente, a natureza será motivo de interesse para o artista, assim como o chamado quadro de gênero que enfoca a vida social e o indivíduo no seu habitat natural.

Vão sendo deixadas de lado as pinceladas lisas e as veladuras. O desenho, mesmo o mais minucioso, omite certos detalhes tornando-se quase imperceptível. As massas vão sendo representadas por pinceladas mais largas, gestuais, pastosas, 
explorando os efeitos das cores na luz - que dilui o próprio contorno das formas - e na sombra, que começa a incorporar as cores complementares da cor do objeto que as projetava. A paleta vai aos poucos abandonando os tons escuros e se tornando mais luminosa, mais vibrante, mais colorida, revelando o caráter expressivo da matéria cromática.

As transformações das condições e dos efeitos da criação artística se fazem notar, especialmente a partir da década de 1910, com a valorização de uma arte "nacional", reforçada no pós-guerra. Nesse período, começam a surgir na capital paulista os debates em torno de uma "arte nacional", que rejeitava os paradigmas culturais europeus, mais particularmente os franceses, tão fortemente incorporados no período da Belle Époque. A presença na cidade de muitos artistas imigrantes, acirrou as discussões sobre a influência estrangeira nas artes plásticas e a necessidade de valorizar uma arte que contemplasse a "nossa natureza", a "nossa gente", o "nosso meio" (Rossi, 2001).

Um dos primeiros movimentos artístico-culturais, em prol da criação de um estilo autenticamente brasileiro, germinou em São Paulo, na década de 1910, a partir da atuação do arquiteto e arqueólogo português, Ricardo Severo. Em 1914, durante a conferência "A Arte Tradicional no Brasil", que teve lugar na Sociedade de Cultura Artística de São Paulo, Severo lançou as bases de um programa para a arquitetura local, a partir das arquiteturas portuguesa e colonial brasileira, que daria origem, posteriormente, ao estilo neocolonial. Nessa conferência, Ricardo Severo introduziu a questão da valorização dos "elementos tradicionais" da arquitetura brasileira, perdidos no processo de "desnacionalização" ocorrido durante o século XIX, com a importação de modelos europeus:

Não procurem ver [...] nesta veneração tradicionalista [...] uma manifestação de "saudosismo" romântico e retrógrado. Com efeito, para criar uma arte que seja nossa e do nosso tempo, cumprirá, qualquer que seja a orientação, que não se pesquisem motivos, origens, fontes de inspiração, para muito longe de nós próprios, do meio em que decorreu o nosso passado e no qual terá que prosseguir o nosso futuro. (Severo, 1914)

Ao lançar um programa que visava à criação de uma arte que chamou de nossa, Severo parecia não se dar conta de que era europeu e imigrante, assim como a arquitetura "nacional" por ele proposta, que mesclava as arquiteturas portuguesa e colonial brasileira, ambas de matriz lusitana, que não excluíam as correntes estilísticas importadas da Europa.

O caráter "desnacionalizante" da nossa arte seria também uma preocupação constante nos textos de Oswald de Andrade $(1915,1924)$ e Monteiro Lobato (1916a, 1916b, 1917). Em 1915, Oswald reivindica uma forma de expressão para 
a cultura e para a arte com características nacionais, que se afastasse dos padrões consagrados na Europa (O. de Andrade, 1915). Em 1916, Monteiro Lobato reitera e alarga sua postura sobre a arte nacional, que atinge seu ponto alto com a criação da Revista do Brasil, em 1916, trazendo matérias que tratam das questões artístico-culturais voltadas, sobretudo, para a valorização da produção de caráter nacional, o que fica evidente em seu primeiro artigo editorial:

[...] o que há por trás do título desta Revista e dos nomes que patrocinam é uma coisa simples e imensa: o desejo, a deliberação, a vontade firme de constituir um núcleo de propaganda nacionalista. (Lobato, 1916b)

Embora perceptível desde o começo do século XX, é após a eclosão da Primeira Guerra Mundial - quando os sentimentos nacionalistas se exacerbam e com o retorno dos jovens artistas que estudavam na Europa, que se intensificam os debates sobre uma arte autenticamente nacional. Não que se questionasse propriamente as estruturas tradicionais da arte. O que começava a ser discutido era o sistema de disposições passado, estruturado em torno de normas, regras e princípios sociais da cultura europeia.

Esse ideal, entretanto, dificilmente seria alcançado, uma vez que a presença do elemento estrangeiro era evidente não só nos diversos segmentos da nossa sociedade, mas, particularmente no campo das artes plásticas.

\section{O MODERNISMO}

Discorrer sobre o movimento modernista soa temerário. A bibliografia sobre o tema é extensa, e desde os primeiros bancos escolares defrontamo-nos com ele nos livros didáticos, como um marco na história da nossa arte e da nossa cultura. Comentado ao longo dos anos por afetos e desafetos, a multiplicidade de enfoques que o tema já recebeu e vem recebendo, parece supor que o seu sentido e significado não foram ainda totalmente apreendidos. Veja-se, portanto, nestas linhas, não o interesse em se fazer uma revisão da Semana, do movimento e de seus desdobramentos. Nosso intuito é apenas o de situar um evento artístico no complexo processo de formação da nossa cultura e identidade nacionais.

A Semana de Arte Moderna, realizada em São Paulo, entre 11 e 18 de fevereiro de 1922, fez parte da agenda oficial comemorativa do Centenário da Independência, assim como a Exposição Universal, que teve lugar no Rio de Janeiro.

As propostas, expostas no artigo Maré das reformas, de Menotti Del Picchia, foram assim resumidas por Mário da Silva Brito: 
a) o rompimento com o passado, ou seja, a repulsa às concepções românticas, parnasianas e realistas; b) independência mental brasileira através do abandono das sugestões europeias, mormente as lusitanas e gaulesas; c) uma nova técnica para a representação da vida em vista de que os processos antigos ou conhecidos não apreendem mais os problemas contemporâneos; d) outra expressão verbal para a criação literária, que não é mais a mera transcrição naturalista mas recriação artística, transposição para o plano da arte de uma realidade vital; e) e, por fim, a reação ao status quo, quer dizer, o combate em favor dos postulados que apresentava, objetivo da desejada reforma. (Brito, 1978)

Participaram da Semana, no âmbito das artes plásticas, Victor Brecheret e Wilhelm Haerberg, na seção de escultura, Anita Malfatti, Di Cavalcanti, John Graz, Martins Ribeiro, Zina Aita, J. F. de Almeida Prado, Ferrignac e Vicente do Rego Monteiro, na seção de pintura, apresentando uma produção heterogênea. Segundo Aracy Amaral, as obras apresentadas não obedeciam a "diretrizes, nem certezas", ao contrário, "as oscilações eram muitas" e "várias eram as tendências" (Amaral, 1998).

Anita Malfatti, considerada a precursora do movimento, levou para a Semana várias obras já conhecidas da crítica e do público paulistanos em exposições anteriores realizadas na capital, especialmente as apresentadas na exposição de dezembro de 1917. Assim como Anita, Rego Monteiro, que se encontrava em Paris em fevereiro de 1922, enviou para a exposição obras que fizeram parte da sua mostra realizada em maio de 1920 na capital, de tendências "cubistas" e "divisionistas" e de assuntos brasileiros populares e lendários. As oscilações apontadas por Aracy Amaral estavam presentes também nas obras de Di Cavalcanti, já conhecido na capital desde 1917, pelos trabalhos de ilustração e pelas exposições que realizou, e nas do também ilustrador e caricaturista Ferrignac (Ignácio da Costa Ferreira), cujo único trabalho exposto, Natureza dadaísta, levou a autora de Artes Plásticas na Semana de 22 a acreditar que se tratasse, não de uma proposta relacionada ao grupo niilista surgido na Primeira Guerra Mundial, mas de um "trabalho reunindo o máximo de extravagância, com uma certa dose do 'moderno' mundano como era do gosto de Ferrignac" (Amaral, 1998).

Da exposição no Municipal participou ainda outro artista que se apresentara na capital, em 1920: o pintor suíço John Graz. Dono de uma técnica amadurecida e de um estilo particular, foi muito bem recebido pela crítica paulistana na ocasião. Até onde nos foi dado conhecer, o único parecer desfavorável ao seu trabalho partiu do Jornal do Comércio (Edição de São Paulo), do dia 20 de dezembro de 1920. Este artigo, transcrito parcialmente por Mário da Silva Brito, nos diz que seus temas "obedecem a um desequilíbrio de linhas muito acentuado, próprio das primeiras eras” (Brito, 1978). 
Patrocinada pelos mais importantes protagonistas da elite dirigente, a $\mathrm{Se}$ mana de Arte Moderna teve pouco de moderno, e nada na sua realização pode ser entendida como uma reação ao status quo, como as propostas do grupo pretendiam. Esteve longe, ainda, de atingir a "independência mental brasileira através do abandono das sugestões europeias". As obras dos principais participantes da Semana, como Victor Brecheret, Anita Malfatti, John Graz, Zina Aita e Vicente do Rego Monteiro, estavam impregnadas das influências estrangeiras, adquiridas durante seus aprendizados na Europa.

A principal tribuna das propostas modernistas foram os jornais Correio Paulistano, propriedade do PRP, partido do governo e o Jornal do Comércio, cuja direção estava a cargo de René Thiollier, integrante da elite dominante. A Semana realizou-se no mais importante teatro de São Paulo, o Municipal, com o endosso de Graça Aranha, membro da Academia Brasileira de Letras, e com a colaboração de intelectuais filiados ao PRP, como Oswald de Andrade e Menotti Del Picchia e com o patrocínio de Washington Luís, presidente do Estado, Paulo Prado, Antonio Prado Jr., Armando Penteado e René Thiollier, entre outros, que deram apoio financeiro e logístico ao evento.

A rigor, a Semana poderia ser vista como mais um evento levado a efeito na capital pela iniciativa privada, a exemplo das Exposições Brasileiras de Belas Artes, da Exposição de Arte Francesa e de inúmeras mostras artísticas individuais e coletivas, que já contavam nas décadas anteriores com o amparo da burguesia paulistana para as suas concretizações. De Almeida Prado, de forma peremptória nos diz que os ideólogos da Semana "laboriosamente conseguiram transformar evento secundário, semelhante a tantos do mesmo gênero anteriores e posteriores, em sucesso ímpar [...]" (de Almeida Prado, 1996).

A despeito do que relata a historiografia pró-modernismo, a afirmação de Almeida Prado encontra respaldo nas pesquisas sobre o campo artístico paulistano. Antes do advento do modernismo, já havia um crescente movimento artístico na capital de São Paulo. Mas como toda a narrativa construída para comemorar uma vitória está invariavelmente vinculada à narração de uma derrota, esses estudos, além de consolidar a ideia de que o período precedente era indiferente e totalmente desinteressado pela renovação artística, associam-no à conservação estética, à estagnação e ao passadismo, enquanto o modernismo se reveste de inovação, criatividade e autenticidade nacional (Rossi, 2001).

O que se observa, entretanto, do que brevemente expusemos acima, é que as obras expostas na Semana, estavam longe de representar uma "renovação estética". Mesmo a tentativa de Oswald de Andrade, dois anos depois, conclamando 
"a síntese”, "o equilíbrio", "a invenção", "a surpresa", "uma nova perspectiva", "uma nova escala", "a volta ao sentido puro" (O. de Andrade, 1924), não chegou a resultar em fatores destrutivos.

Confundindo o moderno com aspectos meramente formais, o modernismo refletiu a mescla de influências externas, geradas em atmosfera diversa, e influências internas, estas últimas manifestadas sobretudo nos temas nacionais. Cabe aqui lembrar as palavras de Mário de Andrade, que no prefácio de $\mathrm{Macu}$ naíma diz não estar convencido de ter feito obra brasileira, pelo simples fato de ter empregado elementos nacionais (M. de Andrade, 2016).

Decorridos 20 anos da Semana, em 30 de abril de 1942, no Salão de Conferências da Biblioteca do Ministério das Relações Exteriores do Brasil, Mário de Andrade, em um ensaio retrospectivo, denomina de heroico o período compreendido entre a exposição de Anita Malfatti, em dezembro de 1917 e a Semana, em fevereiro de 1922. A segunda fase, que duraria até 1930, foi identificada pelo autor como destruidora, seguida por outra "[...] mais calma, mais modesta e cotidiana, mais proletária, por assim dizer, de construção" (M. de Andrade, 1974, p. 241).

A calma pode ser entendida como serenidade, mas também como apatia, inércia e indiferença; a modéstia caracteriza o despretensioso, o moderado ou aquele que não se sobressai e que ocupa, entre seus iguais, posição de pouco ou nenhum relevo; o cotidiano invoca monotonia, invariabilidade; proletário indica o exercício de um ofício manual ou mecânico, que em suas formas mais especializadas implica técnica, o que no âmbito das artes visuais pressupõe o domínio de um conjunto de processos predefinidos para o seu exercício.

Todas essas variáveis identificam, para um dos expoentes da Semana de 22, a última fase do movimento modernista. Entendida por este viés, a fase "por assim dizer, de construção", curiosamente parece ter se estruturado ao redor de elementos que a historiografia tradicional associa à arte acadêmica.

\section{NOVAS TENDÊNCIAS}

A geração de artistas que surgiu nas duas primeiras décadas do século $\mathrm{XX}$, os chamados "acadêmicos", encontra sua fase de amadurecimento nas décadas subsequentes, atuando paralelamente aos artistas e a movimentos que vão surgindo, como o próprio movimento modernista e os movimentos pró-arte moderna - Manifesto Pau-Brasil (O. de Andrade, 1924) e Manifesto Antropofágico (1928) - e da nova geração que desponta na década de 30, quando constituem-se complexas associações entre artistas e intelectuais oriundos da classe burguesa, 
com amplos objetivos programáticos como a Sociedade Pró- Arte Moderna (SPAM), o Clube dos Artistas Modernos (CAM), facções como a que organizava o Salão de Maio, ou ainda o Grupo Almeida Júnior, o Grupo Seibi-Kai, composto por nipo-brasileiros e a associação formada por artistas vindos, em sua maioria, de atividades artesanais, de origem mais modesta, própria de extratos sociais proletários ou da pequena burguesia, que formaram o Grupo Santa Helena, elemento nuclear de uma aliança maior: a Família Artística Paulista.

Para maior clareza nesta exposição, chamaremos de artistas de tradição todos os artistas que a historiografia trata por "acadêmicos" no sentido de contrapor aos "modernos". De modernos ou modernistas, os artistas associados ao movimento de 22 e de independentes todos os demais que se afastam tanto de uns quanto de outros, incluindo os integrantes dos grupos Santa Helena, Seibi-Kai e Família Artística Paulista. Esta distinção é feita aqui não com o intuito de determinar categorias estéticas, mas para simples efeito de referência.

O Grupo nipo-brasileiro Seibi-Kai e o Grupo Santa Helena, guardam alguma semelhança entre si, na medida em que a maioria de seus integrantes cursou as Escolas Profissionais, o Liceu de Artes e Ofícios e as aulas de desenho e modelo vivo da Sociedade Paulista de Belas Artes. Além desses estudos, os santelenistas aperfeiçoavam-se junto a mestres renomados da capital, como Pedro Alexandrino, Antônio Rocco, Amadeo Scavone, Georg Fisher Elpons, Clóvis Graciano e Waldemar da Costa. Tanto os integrantes do Seibi-Kai, quanto os do Santa Helena, aprendem mais pelo intercâmbio de experiências e pela observação do meio em que vivem, do que propriamente pelo ensino formal.

Os integrantes do Grupo Santa Helena iniciaram, a partir de aproximadamente 1934, um caminho de pesquisas e trocas mútuas, fortalecendo o companheirismo que alguns integrantes do grupo já cultivavam desde a década anterior. A despeito dos ganhos nos estudos da arte, o que predomina nesse grupo, conhecido também por Escola Paulista, por fixarem paisagens paulistanas, é o esforço pessoal de aprimoramento e a elaboração individual própria, marcados pelo estímulo de uma vivência em grupo. Seu trabalho destaca-se pela observação mútua, pela troca de informações e pela pesquisa, voltada mais para a temática e o conteúdo da arte, do que para a renovação formal. O caminho escolhido foi o de expressar o seu próprio cotidiano, numa crônica de ambiência urbana e suburbana, fixando os arredores da cidade, o homem do povo, a cor da terra.

Em novembro de 1937, o grupo, sob a liderança de Paulo Rossi Ozir e Waldemar da Costa, participa do I Salão da Família Artística Paulista, no Hotel Esplanada, ao lado de Joaquim Ferreira, Hugo Adami, Arnaldo Barbosa, Anita 
Malfatti, Arthur P. Krug e Balloni. Em 1939, realiza-se o II Salão da FAP, no Automóvel Clube, com a participação de novos elementos: Portinari, Alfredo Rullo Rizzotti, Domingos Toledo Piza, Nelson Barbosa, Renée Lefèbre, Bernardo Rudofsky, Nelson Nóbrega, Vilanova Artigas e Ernesto de Fiori. A terceira e última exposição da FAP, devido a divergências internas, realizou-se em agosto de 1940, no Palace Hotel do Rio de Janeiro, com seu grupo desfalcado de alguns artistas, mas com novas adesões: Carlos Scliar, Vittorio Gobbis e Bruno Giorgi.

Os artistas que formaram o Grupo Santa Helena, assim como os que com eles integraram a Família Artística Paulista, são vistos pela historiografia que de alguma forma aborda o assunto, como "modernistas moderados", não obstante o elo inegável com a tradição artística, no que se refere à forma, ao conteúdo, à pesquisa técnica e ao embasamento artesanal do ofício.

Faltam estudos que avaliem de que forma esses diversos artistas, agrupamentos e movimentos interagiram entre si e com os circuitos de produção, circulação, divulgação, representação e consumo, e como definiram posições, conceitos e interesses específicos. Fatos isolados, contudo, demonstram que no decorrer das décadas de 20 e 30, artistas de tradição, modernistas e independentes estiveram juntos em inúmeros eventos artísticos realizados na capital paulista, trabalhando ao mesmo tempo e no mesmo espaço.

As mostras artísticas da Sociedade Paulista de Belas Artes, fundada em 1921, promotora da principal exposição coletiva da cidade até o fim da década de 1940 (Zanini, 1991), reuniam tanto artistas de tradição quanto modernistas e independentes. Quando, em 12 de agosto de 1936, essa Sociedade é transformada em órgão sindical dos artistas plásticos de São Paulo, em função da legislação trabalhista em vigor, continuou contanto com a adesão concomitante de artistas de tradição, modernos e independentes, que se revezavam inclusive na sua direção. Seu primeiro presidente, foi o artista de tradição Paulo Vergueiro Lopes de Leão. A modernista Anita Malffati ocupou a direção em 1942, mas antes disso, em 1935, o nome de Anita encontra-se entre os integrantes do Grupo Almeida Júnior.

$\mathrm{O}$ encontro entre artistas que expressavam tendências diversas, aliado à colaboração das elites paulistanas, ocorre também na exposição organizada pela Società Italiane di Cultura Muse Italiche, realizada no Palácio das Indústrias, em maio de 1928. A mesma situação se repetiria no Salão Paulista de Belas Artes, criado em 25 de janeiro de 1934, por decreto do Governo do Estado. Os artistas de tradição, os modernos e os independentes estarão, por longo tempo, tanto entre os participantes quanto entre os dirigentes (Shinsato,1986). 
Mesmo as breves tentativas de intercâmbio exclusivamente voltadas para a arte moderna, ocorridas na década de 30, como o CAM (1932-1933), a SPAM (1932-1934) e os Salões de Maio (1937-1939), contaram muitas vezes com a participação e a colaboração de artistas de tradição e/ou independentes.

\section{CONSIDERAÇÕES FINAIS}

Muito se procurou, e se procura, a autêntica identidade brasileira. Nesse percurso, o índio, o negro, o português, o estrangeiro, ora foram denegridos, ora enaltecidos. Parece-nos, contudo, que a formação da cultura e da identidade de um povo não pode ser localizada em um ou em alguns agentes. Ela é forjada em um amplo contexto e é subordinada a um longo processo histórico sob as mais variadas formas em todos os campos.

Transitando pelo universo simbólico do qual emergem as formas e as representações estéticas, partimos do pressuposto de que a arte promove o encontro do homem consigo mesmo e com a sua cultura, e que as manifestações estéticas de uma sociedade, quando em sintonia com o momento histórico, são capazes de revelar a sua essência no que ela tem de material e imaterial. A reflexão sobre a nossa cultura e identidade tem sido marcada pelo senso dos contrastes e mesmo dos contrários, como condições antagônicas em função das quais se ordena a história dos homens e das instituições.

Essas ambiguidades, que parecem apontar para um descompasso entre as ideias e o lugar e que sempre marcaram a formação da sociedade brasileira, não querem dizer que sejamos uns desterrados em nossa terra ou uns deploráveis imitadores. São apenas manifestações legítimas das condições históricas em meio às quais se desenvolvem as práticas e as representações. Como no Sonho de Einstein, o caminho da nossa cultura e o sonho da autenticidade nacional, carregam consigo a textura pegajosa do tempo.

\section{REFERÊNCIAS}

Amaral, A. A. (1998). Artes Plásticas na Semana de 22 (5a ed.). Ed. 34.

Bourdieu, P. (1992). A Economia das trocas simbólicas (3a ed.). Perspectiva.

Bourdieu, P. (1996). Razões práticas. Sobre a teoria da ação. Papirus.

Bourdieu, P., \& de Saint Martin, M. (1976). Anatomie du goût. Actes de la recherche en Sciences Sociales, 2(5), 2-81. https://doi.org/10.3406/arss.1976.3471 
Brito, M. da S. (1978). História do Modernismo Brasileiro: I. Antecedentes da Semana de Arte Moderna (5a ed.). Civilização Brasileira.

de Almeida Prado, Y. (1996). A grande Semana de Arte Moderna (Depoimentos e subsídios para a cultura brasileira). Edart.

de Andrade, M. (2016). Macunaíma. Poeteiro.

de Andrade, M. (1974). Aspectos da Literatura brasileira. São Paulo/Brasília: Martins/MEC.

de Andrade, O. (1915, 2 de janeiro). Em Prol de uma Pintura Nacional. O Pirralho, (168), p. 2.

de Andrade, O. (1924, 18 de março). Manifesto Pau-Brasil. Correio da Manhã.

de Holanda, S. B. (1991). Raizes do Brasil (23a ed.). José Olympio.

de Vasconcelos, S. (1969). Civilização das Minas Gerais. Revista Brasileira de Estudos Políticos, 25/26 (84), 81-136.

Del Picchia, M. (1920, 10 de abril). Da Estética: Seremos plagiários? Correio Paulistano, 1.

Freyre, G. (2006). Casa Grande \& Senzala. Colección Archivos.

Gorender, J. (1985) O Escravismo Colonial (4a. ed.). Ática.

Lightman, A. (1996). Sonhos de Einstein. Companhia da Letras.

Lima, A., Jr. (1985). A Capitania das Minas Gerais. Zelio Valverd.

Lobato, M. (1916a, 9 de janeiro). A propósito de Wasth Rodrigues. O Estado de São Paulo, 5.

Lobato, M. (1916b). Dois Pintores Paulistas. Revista do Brasil, (12), 395-403.

Lobato, M. (1917). Almeida Júnior. Revista do Brasil, (13), 35-52.

Needell, J. D. (1993). Belle Époque Tropical: sociedade e cultura de elite no Rio de Janeiro na virada do século. Companhia das Letras

Prado, P. (2006). Retrato do Brasil: Ensaio sobre a tristeza brasileira. eBooksBrasil. http://www.ebooksbrasil.org/eLibris/pauloprado.html

Rossi, M. S. (2001). Organização do campo artístico paulistano [Dissertação de mestrado, Universidade de São Paul]. Biblioteca Virtual da FAPESP. http://www.teses.usp.br/teses/disponiveis/8/8132/tde-18122013-135814/

Rossi, M. S. (2013). A gênese do campo artístico paulistano: Entre vanguarda e tradição. Sceculum Revista de História, (28), 195-210.

Severo, R. (1914, 4, jan.-abr.). A Arte Tradicional no Brasil. Revista do Brasil, ano II, vol. 1917, 394- 424.

Shinsato, M. K. (1986) O Salão Paulista de Belas-Artes e os grandes artistas de todas as tendências que por ele passaram. IMESP.

Zanini, W. (1991). A Arte no Brasil nas décadas de 1930-40: O Grupo Santa Helena. Nobel; Editora da Universidade de São Paulo. 